\title{
Research on production efficiency of solanum and gourd vegetables based on DEA: A case study of Guangzhou
}

\author{
Xiujie Huang ${ }^{1, \text { a }}$, Yangyang Liu $^{2, *}$, Xialing Chu ${ }^{1, b}$ \\ ${ }^{1}$ Institute of Agricultural Economics and Rural Development, Guangdong Academy of Agricultural \\ Sciences, Guangzhou 510640, China \\ 2 School of Humanities and Development, China Agricultural University, Beijing 100193, China \\ a124851033@qq.com, b158283003@qq.com
}

\begin{abstract}
A vertical analysis was conducted on the production efficiency changes (2004-2013) of three solanum and gourd vegetables - tomato, cucumber and eggplant of Guangzhou City by using DEA-Malmquist Index method. Meanwhile, in this paper, a horizontal analysis on the production efficiency (of 2012) of the three vegetables of Guangzhou was conducted by using DEA-BC2 model based on input. The results showed that: (1)From 2004 to 2013, the increasing rates of annual average total factor productivity and annual average technical progress were above 0; (2)Technical progress was the main driving force of total factor productivity, which was less affected by technical efficiency. (3) In 2012, the cucumber production of Guangzhou achieved optimal scale efficiency and optimal comprehensive technical efficiency while open field tomato and eggplant production did not reach optimal pure technical efficiency because of unreasonable allocation of resources and the excessive input of factors such as excess of material and service costs, labor costs, land costs and so on.
\end{abstract}

Keywords: Data envelopment analysis; production efficiency; vegetable industry.

\section{Introduction}

With abundant vegetable resources and located in the subtropical regions, Guangdong is a major vegetable production province in China and is suitable for planting different varieties of vegetables all the year round. The vegetable output value in Guangdong Province accounts for about half of its gross value of agricultural output. Vegetable industry has not only promoted Guangdong agricultural economy and become an important channel for farmers to increase income, but also ensured the vegetables supply source for the consumers' increasing demand. The vegetable planting area in Guangdong was 1.3069 million hectares and output was 31.445 million tons in 2013, ranking in the top 10 of all provinces throughout the country. Moreover, Guangzhou is an important area of vegetable production in Guangdong because its perennial vegetable acreage and production accounted for $10.7 \%$ and $10.9 \%$, respectively on the top of Guangdong. However, as planting vegetables requires high water consumption and is labor-intensive, the long-term development of vegetable industry must be also considered for the limited water resources, land resources, personnel resources although the rainfall is relatively abundant in Guangzhou. For this purpose, it is of great significance to improve input and output efficiency of vegetable production and achieve agricultural modernization, and to improve agriculture-related policies and measures with the scientific evaluation of vegetable industry production efficiency in Guangzhou, by putting forward the improvement measures and using less land resources, water resources and other agricultural inputs to produce more high-quality vegetables.

There are many literatures on the efficiency of agricultural production in domestic research, but few studies on the efficiency of vegetable production. Zhang Tao used DEA method to measure and compare the vegetable production technical efficiency of China and Japan in 2000, it was concluded that the average technical efficiency of Chinese vegetable production in 2000 was 0.83 , below the average level of Japan ${ }^{[1]}$. Li Qin-zhi used the DEA method to calculate the production efficiency of China's potato producing areas during the period of 1998-2005, it was concluded that the technical efficiency of potato production achieved positive growth, with an average annual growth rate of $0.8 \%$ 
${ }^{\text {[2] }}$ Xu Jia-peng and Li Chong-guang used stochastic frontier production function model to calculate the technical efficiency of vegetable production in China ${ }^{[3]}$. The results showed that the technology of vegetable production in our country presented the "central collapse" phenomenon-the unreasonable input of each factor in the production of vegetable was the main reason for the lack of efficiency of the production technology. The study of Sun Rui-hua etc showed that compared with the rest of the country, the open field vegetable in Shandong province had certain comparative advantage on the input and output, while facility vegetables had comparative advantage in the comprehensive efficiency and scale efficiency, and both were in the incremental stages of scale of remuneration ${ }^{[4]}$. Wang Huan and Mu Yue-ying's research results showed higher the production efficiency and economic value in greenhouse vegetable production at current stage but a lower level of overall efficiency vegetable production in Beijing ${ }^{[5]}$.

Currently, most of the researches of vegetable production efficiency focused on the macroscopic researches of national vegetable production efficiency but less on the production efficiency of specific vegetables in a given area. There are great differences in production efficiency of various vegetables because of different climate and different resources. The comparison and analysis on the production efficiency of three vegetables of Guangzhou will provide references for the development of vegetable industry of Guangzhou and other areas. Therefore, the dynamic changes of total factor production efficiency of three representative vegetables in Guangzhou (2004-2013) was measured by using DEA-Malmquist index method based on current researches. Moreover, decomposition of technical efficiency and technical progress were performed for these dynamic changes to explore the underlying reasons of efficiency changes and corresponding improvement methods towards a useful supplement for current researches.

\section{Summary of research method and Data sources}

\subsection{Summary of research method.}

Data envelopment analysis (DEA) is an effective method for evaluating relative efficiency of complex system with similar types and multiple inputs and outputs and is currently widely used in the evaluation of productive efficiency. DEA includes two basic models: $\mathrm{BC}^{2}$ model of variable returns to scale (also called VRS model ) and $\mathrm{C}^{2} \mathrm{R}$ model of consistent returns to scale (also called CRS model).

Malmquist total factor productivity index, named after Swedish statistician--Malmquist, is defined by Fare et al. based on the Output Distance Function of Shephard ${ }^{[6]}$. It is a productivity index covering all kinds of production factors and defined as the rate between total outputs and total inputs. From period $t$ to period $t+1$, Malmquist index for measuring total factor productivity (TFP) can be calculated as follow:

$$
M_{0}\left(x_{t+1}, y_{t+1}, x_{t}, y_{t}\right)=\left[\frac{d_{0}^{t}\left(x_{t+1}, y_{t+1} \mid C\right.}{d_{0}^{t}\left(x_{t}, y_{t} \mid C\right)} \times \frac{d_{0}^{t+1}\left(x_{t+1}, y_{t+1} \mid C\right)}{d_{0}^{t+1}\left(x_{t}, y_{t} \mid C\right)}\right]^{\frac{1}{2}}
$$

In the above formula, $\left(x_{t+1}, y_{t+1}\right)$ and $\left(x_{t}, y_{t}\right)$ represent the input and output vectors of period $t+1$ and period $t$ respectively; $d_{0}{ }^{t}$ (or: $d_{0}{ }^{t+1}$ ) represents, to the technique of period $t$, the distance function of period $t$ (or: $t+1$ ). If the index is above 1 , it indicates that TFP is increasing from period $t$ to period $t+1$. According to the concept of Fare, the index can be decomposed into technical efficiency change index (EC) and technical progress change index (TP), and the former can be further divided into pure technical efficiency index (PC) and scale technical efficiency change index (SC). SC means the degree of economy of scale by comparing a certain production point and its scale efficiency point. If the technical efficiency is equal to 1 , it indicates that decision-making unit(DMU) scale is efficient, namely, the inputs of vegetable production is in a proper manner and the returns to scale is the best. PC reflects the level of operation management and production technology of a certain production point comparing to other technical efficiency point. If PC is equal to 1 , that means it is an effective unit technology, namely, the status of vegetable production is in a best manner, achieving the maximum production output. Conversely, the unit technology is noneffective. Technical efficiency is 
a reflection of technology update rate and effectiveness of technology promotion. The value of EC, PC, and SC is between 0 and 1; the higher value indicates the higher efficiency. The DMU will be an effective DEA unit while achieving the goal of "technical efficiency" and "scale efficiency"; if any of the two is one, it is a less effective DEA unit; if none of value is 1 , it is a noneffective DEA unit.

\subsection{Data sources and index selection.}

In this paper, all of the data was selected from the Compilation of Cost-Benefit of National Agricultural Products. Considering the availability of the data, the data (from 2004 to 2013) of production input and output of those three chief vegetables--tomato, cucumber and eggplant has been selected. Related data of tomato of 2010 was substituted by the average of the data of 2004-2009 and 2011-2013 because of the data loss of 2010.

Considering the relative importance of all the input and output factors during vegetable planting, the output value of vegetable (per acre) was chosen as output variable and the material and service costs (per acre), labor cost (per acre) and land cost (per acre) as input variables. Material and service costs are composed of direct and indirect costs, direct costs include the costs of seeding, fertilizer, farmyard manure, pesticide, agricultural film and operation renting (mechanical operation cost, irrigation fees, ploughing fees), fuel and power, technical service, tools and materials, maintenance and repair and other direct costs. Indirect costs include fixed-asset depreciation, insurance costs, overheads, sales and financial expenses. Labor costs include family labor and employees; Land costs (per acre) include land circulation and self-owned land renting ${ }^{[7]}$. The designed indexes of this paper can reflect the cost of vegetable planting objectively and there is no significant correlation between input and output indexes. As such, the proper number of DMU can reflect the facts effectively.

\section{Vertical analysis on the production efficiency of three vegetables in Guangzhou (2004-2013)}

\subsection{Analysis on detecting results of related production efficiency.}

Under the circumstance of CRS, the production efficiency and relative indexes of tomato, cucumber and eggplant of Guangzhou City (during 2004-2013) were measured by Malmquist Index Method from the perspective of input as indicated in Table 1.

The following aspects were analyzed based on the data of table 1.

Firstly, from the perspective of technical efficiency, from 2004 to 2008, DEA of tomato was in a noneffective status; from 2008 to 2013, with significant improvement of technical efficiency, DEA was in an effective (or nearly effective) status. (2) From 2004 to 2013, DEA effectiveness and DEA effectiveness of eggplant was in a reciprocation status. (3) From 2004 to 2013, cucumber remained in an effective DEA status, which meant the technical efficiency and scale efficiency were the best, namely, the proper production input of cucumber guaranteed the maximum output and the returns to scale was also the best.

Secondly, from the perspective of technical progress changes, from 2004 to 2013, the average of technical progress changes of the three vegetables (tomato, cucumber and eggplant) were above 1 . In general, technical progress has been achieved during planting of these three vegetables from 2004 to 2013. (2) However, in some years, the average of technical progress changes of the three vegetables were less than 1 , which indicated that there were some technical setbacks compared to the previous year. (3) There were high similarities in technical progress changes of the three vegetables, with an reciprocation of rising and falling.

Thirdly, from the perspective of pure technical progress change, from 2004 to 2008, majority of the PEch of tomato was less than 1, which indicated that the output of tomato was not in an optimum state. The goal of "optimal resource allocation" has not been achieved because of insufficient technical application and ineffective management. While the pure technical progress efficiency of tomato from 2008 to 2013 has increased steadily and in a state of technical efficiency, which showed that the technical application efficiency and management efficiency of tomato planting have improved evidently. (2) From 2004 to 2009, the PEch of eggplant was in a state of fluctuation around 1, while the PEch was almost (or nearly) in a optimum state during period of 2009-2013. (3) In 
2004-2013, the PEch of cucumber remained 1, which indicated the unit technology was effective, achieved the maximum output (compared to input).

Fourthly, from the perspective of scale efficiency change (SEch), from 2004 to 2013, average of SEch of tomato, eggplant and cucumber were 1.012, 0.970, and 1 respectively, the average SEch of the three vegetables was 0.994. (2) Comparing to 2004-2008, SEchs of tomato and eggplant were nearly 1 or above 1 . It implied that SEchs of these two vegetables has increased since 2009 and the production scale of which became the optimal scale. (3) SEch of cucumber remained 1, being a state of scale efficiency.

Tab. 1 Decomposition of Malmquist productivity indexes of three vegetables in Guangzhou (2004-2013)

\begin{tabular}{|c|c|c|c|c|c|c|c|c|c|}
\hline $\begin{array}{c}\text { Type of } \\
\text { vegetable }\end{array}$ & Year & $\begin{array}{l}\text { Technical } \\
\text { efficiency } \\
\text { change } \\
\text { (Effch) }\end{array}$ & $\begin{array}{l}\text { Increasing } \\
\text { rate of } \\
\text { technical } \\
\text { efficiency }\end{array}$ & $\begin{array}{c}\text { Technical } \\
\text { progress } \\
\text { change(Tch) }\end{array}$ & $\begin{array}{l}\text { Increasing } \\
\text { rate of } \\
\text { Technical } \\
\text { progress } \\
\text { change } \\
\end{array}$ & $\begin{array}{c}\text { Pure } \\
\text { technical } \\
\text { progress } \\
\text { change(PEch) }\end{array}$ & $\begin{array}{c}\text { Scale } \\
\text { efficiency } \\
\text { change } \\
\text { (SEch) }\end{array}$ & $\begin{array}{c}\text { Total factor } \\
\text { productivity } \\
\text { change(TFPch) }\end{array}$ & $\begin{array}{l}\text { Increasing } \\
\text { rate of total } \\
\text { factor } \\
\text { productivity }\end{array}$ \\
\hline \multirow{10}{*}{ tomato } & 2004-2005 & 0.500 & -0.500 & 1.483 & 0.483 & 0.973 & 0.514 & 0.642 & -0.358 \\
\hline & 2005-2006 & 0.611 & -0.389 & 1.448 & 0.448 & 0.688 & 0.889 & 0.885 & -0.115 \\
\hline & $2006-2007$ & 2.175 & 1.175 & 0.888 & -0.112 & 1.670 & 1.482 & 2.050 & 1.050 \\
\hline & 2007-2008 & 0.374 & -0.626 & 1.450 & 0.450 & 0.366 & 1.021 & 0.505 & -0.495 \\
\hline & 2008-2009 & 2.003 & 1.003 & 0.909 & -0.091 & 2.322 & 0.949 & 2.001 & 1.001 \\
\hline & $2009-2010$ & 0.995 & -0.005 & 1.102 & 0.102 & 1.111 & 0.896 & 1.096 & 0.096 \\
\hline & $2010-2011$ & 1.622 & 0.622 & 1.359 & 0.359 & 1.381 & 1.175 & 2.204 & 1.204 \\
\hline & 2011-2012 & 0.998 & -0.002 & 0.622 & -0.378 & 1.030 & 0.969 & 0.521 & -0.479 \\
\hline & $2012-2013$ & 1.124 & 0.124 & 0.862 & -0.138 & 1.086 & 1.035 & 0.856 & -0.144 \\
\hline & Average & 1.013 & 0.156 & 1.013 & 0.124 & 1.001 & 1.012 & 1.027 & 0.196 \\
\hline \multirow{10}{*}{ eggplant } & 2004-2005 & 1.021 & 0.021 & 1.043 & 0.043 & 1.159 & 0.881 & 1.065 & 0.065 \\
\hline & 2005-2006 & 0.609 & -0.391 & 1.538 & 0.538 & 0.460 & 1.326 & 0.937 & -0.063 \\
\hline & 2006-2007 & 1.426 & 0.426 & 0.725 & -0.275 & 1.419 & 1.005 & 1.035 & 0.035 \\
\hline & $2007-2008$ & 0.751 & -0.249 & 1.375 & 0.375 & 1.533 & 0.490 & 1.033 & 0.033 \\
\hline & 2008-2009 & 0.895 & -0.105 & 0.909 & -0.091 & 0.439 & 2.041 & 0.814 & -0.186 \\
\hline & $2009-2010$ & 1.153 & 0.153 & 1.141 & 0.141 & 0.970 & 1.189 & 1.316 & 0.316 \\
\hline & $2010-2011$ & 1.164 & 0.164 & 1.522 & 0.522 & 1.008 & 1.155 & 1.772 & 0.772 \\
\hline & 2011-2012 & 0.943 & -0.057 & 0.557 & -0.443 & 0.970 & 0.972 & 0.526 & -0.474 \\
\hline & $2012-2013$ & 1.179 & 0.179 & 0.763 & -0.237 & 1.121 & 1.052 & 0.900 & -0.100 \\
\hline & Average & 0.987 & 0.016 & 1.008 & 0.06 & 1.018 & 0.970 & 0.995 & 0.044 \\
\hline \multirow{11}{*}{ cucumber } & 2004-2005 & 1.000 & 0.000 & 1.039 & 0.039 & 1.000 & 1.000 & 1.039 & 0.039 \\
\hline & 2005-2006 & 1.000 & 0.000 & 1.693 & 0.693 & 1.000 & 1.000 & 1.693 & 0.693 \\
\hline & $2006-2007$ & 1.000 & 0.000 & 0.804 & -0.196 & 1.000 & 1.000 & 0.804 & -0.196 \\
\hline & $2007-2008$ & 1.000 & 0.000 & 1.354 & 0.354 & 1.000 & 1.000 & 1.354 & 0.354 \\
\hline & 2008-2009 & 1.000 & 0.000 & 0.909 & -0.091 & 1.000 & 1.000 & 0.909 & -0.091 \\
\hline & 2009-2010 & 1.000 & 0.000 & 1.083 & 0.083 & 1.000 & 1.000 & 1.083 & 0.083 \\
\hline & $2010-2011$ & 1.000 & 0.000 & 1.482 & 0.482 & 1.000 & 1.000 & 1.482 & 0.482 \\
\hline & 2011-2012 & 1.000 & 0.000 & 0.568 & -0.432 & 1.000 & 1.000 & 0.568 & -0.432 \\
\hline & 2012-2013 & 1.000 & 0.000 & 0.815 & -0.185 & 1.000 & 1.000 & 0.815 & -0.185 \\
\hline & Average & 1.000 & 0.000 & 1.029 & 0.083 & 1.000 & 1.000 & 1.029 & 0.083 \\
\hline & $\begin{array}{c}\text { Total } \\
\text { average }\end{array}$ & 1.000 & 0.057 & 1.017 & 0.089 & 1.006 & 0.994 & 1.017 & 0.108 \\
\hline
\end{tabular}

Fifthly, from the perspective of total factor productivity change, the averages of increasing rate of total factor productivity of tomato, cucumber and eggplant were $0.196,0.044$ and 0.083 (all above 0 ) respectively, which indicated that the averages of increasing rate of total factor productivity of these three vegetables increased. (2) The increasing rate of total factor productivity and technical progress of the three vegetables was similar and there was significant correlation between the two factors and the correlation coefficient was 0.880 . Both of the increasing rates of total factor productivity and technical progress of tomato were above 0 , with increasing rates of $19.6 \%$ and $12.4 \%$ respectively. 
The annual average technical efficiency was on positive increase with an increasing rate of $15.6 \%$. Also, the increasing rates of total factor productivity and technical progress of eggplant were on positive growth with increasing rates of $4.4 \%$ and $6 \%$ respectively. The annual average increasing rate of technical efficiency was $1.6 \%$, less affected by technical efficiency. The increasing rates of total factor productivity and technical progress of cucumber were on positive growth with increasing rates of $8.3 \%$ and $8.9 \%$ respectively (remains in a state of technical effectiveness). As such, technical progress was the main driving force of total factor productivity changes, which was less affected by technical efficiency.

\section{Horizontal analysis on the production efficiency of three vegetables of Guangzhou City (2012)}

In order to compare and analyze the production efficiency of the three vegetables (tomato, cucumber and eggplant), the research analyzed the input and output data of them in Guangzhou City (2012) from the perspective of input based on DEA method. The effective DEA decision-making units (DMUs) were calculated based on $\mathrm{BC}^{2}$ model of DEA. The 'Production Frontier' was composed of the DMUs. Strategies were put forward to improve other ineffective DMUs of DEA. Such strategies can be achieved by radial movement and slack variables. The DEA-BC ${ }^{2}$ analysis on input and output data was conducted by DEAP Version 2.1 software, the results were as indicated table 2.

Tab. 2 Evaluation form of production efficiency of three vegetables in Guangzhou City (2012)

\begin{tabular}{ccccc}
\hline Type of vegetable & $\begin{array}{c}\text { Technical } \\
\text { efficiency (Effch) }\end{array}$ & $\begin{array}{c}\text { Pure technical } \\
\text { progress } \\
\text { change(PEch) }\end{array}$ & $\begin{array}{c}\text { Scale efficiency } \\
\text { change(Sech) }\end{array}$ & $\begin{array}{c}\text { Returns } \\
\text { to scale }\end{array}$ \\
\hline tomato & 0.890 & 0.966 & 0.921 & irs \\
eggplant & 0.555 & 0.951 & 0.584 & irs \\
cucumber & 1.000 & 1.000 & 1.000 & - \\
\hline
\end{tabular}

Note: “-” represents consistent returns to scale; “irs” represents increasing returns to scale.

As indicated in table 2, the DEA-BC ${ }^{2}$ cucumber was effective, namely, Effch was equal to 1 $($ Effch $=1)$ and the returns to scale was consistent. The technical efficiency of tomato was 0.890 and the technical efficiency of eggplant was only 0.555 . Both of the pure technical progress efficiency and scale efficiency of tomato and eggplant were less than 1, which is not a state of technical effectiveness and scale effectiveness, namely, the optimal outputs (compared to inputs) of tomato and eggplant planting have not been achieved because of excessive inputs or insufficient output (DEA ineffectiveness). Meanwhile, the industry scale of these two vegetables was small and the return to scale was increasing. The production scale needed to be enlarged to improve technical efficiency.

Based on the above analysis, further researches needed to be conducted on tomato and eggplant of technical ineffectiveness to obtain the improvement reference data of input and output factors, achieving the effective DEA-BC ${ }^{2}$ model of vegetable production. Detailed improvement measures for input and output were as indicated in Table 3 and Table 4:

Tab. 3 Improvement reference data for input and output factors of tomato of Guangzhou City (2012)

\begin{tabular}{ccccccc}
\hline & Items & $\begin{array}{c}\text { Original } \\
\text { value }\end{array}$ & $\begin{array}{c}\text { Radial } \\
\text { change }\end{array}$ & $\begin{array}{c}\text { Slack } \\
\text { variables }\end{array}$ & $\begin{array}{c}\text { Target } \\
\text { value }\end{array}$ & $\begin{array}{c}\text { Change } \\
\text { rate(\%) }\end{array}$ \\
\hline $\begin{array}{c}\text { Output } \\
\text { Index }\end{array}$ & $\begin{array}{c}\text { Total production value } \\
\text { (Yuan/mu) }\end{array}$ & 11687.87 & 0.00 & 1003.96 & 12691.83 & -8.59 \\
& $\begin{array}{c}\text { Material and service } \\
\text { cost (Yuan/mu) }\end{array}$ & 1034.21 & -34.69 & -345.08 & 654.45 & 36.72 \\
& $\begin{array}{c}\text { Labor cost (Yuan/mu) } \\
\text { Input }\end{array}$ & 1920.24 & -64.400 & 0.00 & 1855.84 & 3.35 \\
Indexes & Land cost (Yuan/mu) & 220.00 & -7.38 & -47.62 & 165.00 & 25.00 \\
\hline
\end{tabular}

From table 3, it was showed that there were excesses in many input factors of tomato of Guangzhou in 2012. The adjusted amount of material and service cost, labor cost and land cost were 
36.72\%, 3.35\% and 25.00\%. The material and service cost (per acre), labor cost (per acre) and land cost (per acre) were adjusted to 654.45 Yuan, 1855.84 Yuan and 165.00 Yuan respectively. There was insufficiency in outputs. The adjusted amount of total production value was $8.59 \%$, reaching the optimal production value: 11687.87 Yuan/acre.

Tab.4 Improvement reference data for input and output factors of eggplant of Guangzhou City (2012)

\begin{tabular}{ccccccc}
\hline & Items & $\begin{array}{c}\text { Original } \\
\text { value }\end{array}$ & $\begin{array}{c}\text { Radial } \\
\text { change }\end{array}$ & $\begin{array}{c}\text { Slack } \\
\text { variables }\end{array}$ & $\begin{array}{c}\text { Target } \\
\text { value }\end{array}$ & $\begin{array}{c}\text { Change } \\
\text { rate(\%) }\end{array}$ \\
\hline $\begin{array}{c}\text { Output } \\
\text { Index }\end{array}$ & $\begin{array}{c}\text { Total production value } \\
\text { (Yuan/mu) }\end{array}$ & 7414.84 & 0.00 & 5276.99 & 12691.83 & -71.17 \\
& $\begin{array}{c}\text { Material and service } \\
\text { cost (Yuan/mu) }\end{array}$ & 714.04 & -35.23 & -24.36 & 654.45 & \\
& Labor cost (Yuan/mu) & 1952.16 & -96.32 & 0.00 & 1855.84 & 4.93 \\
Input & Land cost (Yuan/mu) & 205.00 & -10.12 & -29.89 & 165.00 & 19.51 \\
\hline
\end{tabular}

From table 4, it was showed that there were excesses in many input factors of eggplant of Guangzhou in 2012. The adjusted amount of material and service cost, labor cost and land cost were 8.35\%, 4.93\% and 19.51\%. The material and service cost (per acre), labor cost (per acre) and land cost (per acre) were adjusted to 654.45 Yuan, 1855.84 Yuan and 165.00 Yuan respectively. There was insufficiency in outputs. The adjusted amount of total production value was $71.17 \%$, reaching the optimal production value: 12691.83 Yuan/acre.

By comparing table 3 and table 4, it was found that (1) the room for improvement of production value of eggplant was much higher than that of tomato, the improvement rates of the two vegetables were $71.17 \%$ and $8.59 \%$. (2) By analyzing the redundancy of input indexes of two vegetables, it was found that the redundancy of material and service cost of tomato was the largest with an amount of $36.72 \%$ while the redundancy of land cost of eggplant was the largest with an amount of $19.51 \%$. (3) By comparing the redundancy of input items of tomato and eggplant, it was found that there was no significant differences in the labor cost redundancy of two vegetables; however, the redundancy of material and service cost of the former was higher than that of the later. Also, land cost redundancy of the former was higher than that of the later with a higher amount of 5.49\%.

\section{Conclusion}

By analyzing the production efficiency of the three vegetables--tomato, cucumber and eggplant of Guangzhou City (2004-2013), conclusions can be drawn as follows:

Firstly, the increasing rates of annual average total factor productivity and annual average technical progress are above 0 . Technical progress is the main driving force of total factor productivity, which is less affected by technical efficiency. In recent years, with the deepening of "Agricultural Science and Technology Project in Villages" and the abundant supply of vegetable for Hong Kong, increasing demands on the quality of vegetables give a great push to the improvement of total factor productivity of Guangzhou City. However, technical efficiency of the three vegetables is lower than expected; in other words, it is the low level of new technology application of vegetable production. There are two main reasons: on one hand, vegetable producers stick to traditional production practice and local government offers less support to agriculture. Agricultural enterprises and farmers' cooperatives and research institutions do not work closely with farmers on technological cooperation. Most of vegetable producers have adapted new technologies; however, the application efficiency of new technology is low due to the poor peasant quality and unfulfillment of agricultural technology extension. On the other hand, most of vegetable producers are individual farmer households with "rental vegetable basis". Most of land tenancy of Guangzhou is 3-5 years, which is much shorter than that (10 years' tenancy) of Ningxia and Henan ect. Therefore, contractors of vegetable basis are not willing to invest on infrastructure construction and production technology of vegetable fields. 
Secondly, in 2012, both of pure technical efficiency and scale efficiency of cucumber of Guangzhou City are 1, which is DEA effectiveness. While pure technical efficiency and scale efficiency of tomato are less than 1 , not reaching the state of technical effectiveness and scale effectiveness, namely, the allocation of production factor is irrational. The excesses of material and service cost, labor cost and land cost results in the less optimal production value, which is because of the complex field management of cucumber. As such, the vegetable producers pay more attention to field management to improve the production efficiency of cucumber. For the excessive input factors of tomato, on one hand, it is the traditional production practice that result in input redundancy. Vegetable production of Guangzhou City depends on extensive production with low scale, industrialization and systematization. The poor-quality vegetable producers believe that "high inputs guarantee abundant outputs, high outputs bring considerable returns”, which results in the excess of input factors. One the other hand, less-advanced agro-technique leads to the excess of material input. Costs of fertilizer and pesticide are the main parts of material and service costs. The fertilization technique of fertilizer and pesticide is less advanced during vegetable production in Guangzhou City while farmers are in pursue of high yield, which lead to the redundancy of material and service costs.

\section{References}

[1] Zhang Tao. Comparison and analysis on vegetable production efficiency of China and Japan, Modern Economic Research. 6 (2004) 37-40.

[2] Li Qin-zhi, Feng Zhong-chao, Li Ran. An analysis on potato production efficiency of China based on DEA, Shaanxi Journal of Agricultural Sciences. 4 (2009) 156-159.

[3] Xu Jia-peng, Li Chong-guang. A study on Technical Efficiency and Influence Factors of China's Vegetable, Collected Essays on Finance and Economics. 3 (2011) 3-7.

[4] Sun Rui-hua, Han Shuai, Chen Qiang. The Production Efficiency Analysis of Vegetable Industry in Shandong Province Based on Data Envelopment Analysis, Henan Science. 6 (2014) 1119-1124.

[5] Wang Huan, Mu Yue-ying. Analysis on Facility Vegetable Production Efficiency and Production Structure in Beijing- Based on Data Collected from Vegetable Farmer Householders, China Vegetables.1 (2015) 45-49.

[6] R. Fare, S. Grosskopf, M. Norris, et al. Productivity growth, technical progress, and efficiency change in industrial ized countries, American Economic Review. 84 (1994) 66-83.

[7] Prices Division of National Development and Reform Commission. Compilation of Cost-benefit of National Agricultural Products, Beijing, China Statistics Press, 2013, pp. 605-608. 